\title{
Prólogo
}

\section{Cincuenta años de la primera vida de Ricardo Palma}

Este año de 2019 la Universidad Ricardo Palma está cumpliendo 50 años de fundada $\mathrm{y}$, al mismo tiempo, se conmemora el Centenario del fallecimiento del ilustre autor de las Tradiciones Peruanas. Por ello, el Instituto Ricardo Palma, para el evento internacional "Re-Visión de las Tradiciones" que se realizará este mes de octubre, está confeccionando un programa de conferencias, mesas redondas y actividades artísticas con motivo de dicho jubileo. En este número decimoséptimo de "Aula Palma" -con los anteriores suma casi trescientos cincuenta artículos dedicados a nuestro gran tradicionista- hay referentes directos sobre dicha conmemoración, en donde participarán destacados especialistas peruanos y extranjeros. El Instituto Ricardo Palma será siempre un referente mundial para ubicar investigaciones del más alto nivel sobre el tradicionista. 
Gracias al inteligente trabajo de los miembros de Número y Correspondientes del Instituto, la imagen de Palma ha adquirido una dimensión extraordinaria debido a los aportes de investigaciones que entregan inéditas luces sobre su vida y su obra. Por otro lado, qué mejor indicativo de nuestra adhesión al próximo Bicentenario patrio que la persistencia de una publicación como "Aula Palma" que se encomienda a un autor clave de nuestra nacionalidad. Las Tradiciones nos muestran en su conjunto la fisonomía espiritual del Perú, con sus diversas tonalidades y características raciales, culturales, geográficas, sociales y políticas, pasando desde el Incario, la Conquista y la Colonia hasta la maduración de una naciente nacionalidad forjada con la espada de la Independencia y acrisolada luego en los vaivenes de la República.

Hace 100 años, en 1919, se empieza a gestar una nueva generación que tendría la marca de la Reforma Universitaria que un año antes (1918) había sido impulsada desde Córdoba, Argentina, hacia todo el Continente. En ese año del 19, estudiantes de la Facultad de Letras de la Universidad San Marcos, entre ellos Jorge Guillermo Leguía y Jorge Basadre, organizaron un ciclo de conferencias sobre el período 1800-1825, que denominaron "Conversatorio Universitario". Estos serían los antecedentes inmediatos de la gran Generación del Centenario (1821-1921).

Esto quiere decir que 1919 marca la muerte de Palma y el nacimiento de una nueva generación que se colocará en la avanzada política, social y literaria del país. Esta generación de Mariátegui y Haya de la Torre reivindicará el legado peruanista de Palma, así como también de Abraham Valdelomar, muerto el mismo año.

El presente número de "Aula Palma" contiene trabajos provenientes del XVII Encuentro Internacional "Re-Visión de las Tradiciones", realizado en octubre del año 2018. La fecha 
de edición, sin embargo, corresponde al año 2019 que coincide con una serie de acontecimientos como el Cincuentenario de la fundación de nuestra Universidad. Los estudios que aparecen en este número incrementan la bibliografía palmista mediante "Ricardo Palma, ¿dueño de un semanario?", de Alberto Varillas; "La incorporación de Ricardo Palma a la Hispanic Society of America en 1907 y la correspondencia cursada hasta 1917", de Arnaldo Mera Ávalos; "Un novedoso hallazgo en la obra de Ricardo Palma: El manuscrito de antología de poesía española de 1893", de Carlos Pérez Garay.

Hay otro conjunto de valiosas entregas que, siguiendo la ruta de los hallazgos, ofrecen nuevas perspectivas y visiones sobre personajes muy cercanos a Palma. Ahí podemos citar "La correspondencia entre Ricardo Palma y Nicolás de Piérola", de Wilfredo Kapsoli; y "Notas sobre la complicidad intelectual de Ricardo Palma y Juana María Gorriti", de Oswaldo Holguín Callo.

Asimismo, se encuentran trabajos cuyas fuentes se sustentan en el análisis de las propias tradiciones, como "El olvidado plato criollo san Pedro y san Pablo", de César Coloma Porcari; "Las paremias en las Tradiciones Peruanas", de Rosario Valdivia PazSoldán; "Los refranes en las Tradiciones Peruanas", de Eduardo Huárag Álvarez; y "El contrato prendario y de beneficencia en la Tradición 'El alacrán de Fray Gómez”, de Iván Rodríguez Chávez.

Otros temas de gran interés como el racial y el parasicológico son enfocados desde una óptica sociológica y psicológica en los trabajos de Roland Forgues (Francia) y de Juan Carlos Adriazola (Piura) que tocan el tema de la negritud; y de Eduardo González Viaña (Perú-Estados Unidos) que estudia la superchería de algunas tradiciones de Palma. 
A dos años de cumplirse el Bicentenario patrio, con los diferentes números de "Aula Palma" y los encuentros anuales de la Re-Visión de las Tradiciones, estamos componiendo el vasto mosaico, el gran mural de la obra y la vida de Ricardo Palma, a la luz de renovados enfoques críticos y metodológicos.

El director 